\title{
Determining equity-linked policy premium for family Takaful: An application of Black-Scholes option pricing with escrowed dynamic model
}

\author{
Jumadil Saputra $^{a^{*}}$, Suhal Kusairi ${ }^{a}$ and Nur Azura Sanusi ${ }^{a}$
}

${ }^{a}$ Faculty of Business, Economics and Social Development, Universiti Malaysia Terengganu, 21030 Kuala Nerus, Terengganu, Malaysia

\begin{tabular}{l}
\hline C H R O N I C L E \\
\hline Article history: \\
Received October 28, 2020 \\
Received in revised format: \\
December 29, 2020 \\
Accepted January 42021 \\
Available online \\
March 24, 2021 \\
\hline Keywords: \\
Insurance premium \\
Equity-linked policy \\
Decision criteria \\
Takaful business model \\
Family takaful
\end{tabular}

\begin{abstract}
A B S T R A C T
The premium is a deterministic function to compensate for losses due to random events and it is an essential part of an insurance company operation. Numerous issues are faced by the Takaful operator in the practice of insurance, one of them is "validity of life insurance" which is still under discussion among Islamic scholars. Their conversation leads to the issue of approach which are utilised by the Takaful operator to create a sales illustration product. Based on their current discussion, there are still some hidden elements and some missing points related to the concept of loss and surplus sharing utilised by Takaful operator. Therefore, this paper focuses on the practice of Family Takaful for producing the sale illustration product which Shariah compliant. The study develops a new model of the premium for an equity-linked policy (Unitlinked product) by considering the properties of Takaful contracts namely Tabarru and Mudarabah. It aims to ensure that a new model developed can comprehensively demonstrate Shariah compliance. The model adapted and derived from the current Takaful Business Model. We add several assumptions to implicate the approach in a real problem associated with the ratio of profit-sharing (Mudarabah) and loss-sharing (Tabarru). Secondary data are used to test and produce a sales illustration product by utilising a new integrated model of the premium developed. Based on the empirical results, a new model of premium is used to create a sales illustration product that comprehensively complies with Shariah and also more profitable and beneficial when compared with a standard approach used by Takaful operator.
\end{abstract}

2021 by the author; licensee Growing Science, Cannda.

\section{Introduction}

The primary objective of life insurance is to provide a benefit, which depends on risk regarding the survival probability of individuals (Hardy, 2003). The risk is a condition attached to the unpredictability with which a person can be afflicted. Providing risk protection against a form of real risks, such as premature death, is extremely important and plays a crucial role in the life insurance policy (Bacinello, Biffis, and Millossovich, 2009). In the natural course of life, most people are exposed to all sorts of risks, which may be unexpected and unforeseen (Khorsid, 2004). This risk can sometimes leave people in vulnerable and helpless conditions (Matsawali et al., 2012). Thus, individuals need to purchase an insurance policy to transfer and minimise their risks, agreeing to pay compensation as protection, otherwise known as the premium (Vaughan and Vaughan, 2007). In the agreement, the insurer will pay a sum of money if the insured faces losses such as accident, injury, or premature death (Zhou and $\mathrm{Wu}, 2008$ ). Life insurance is a concept that does not contradict with the provision of Islam (Khorsid, 2004). In reality, the practice of insurance is similar to the principles of compensation and shared responsibility among societies where most policyholders support each other against unpredictable financial risks which would affect the financial condition of the policyholder's family (Qureshi, 2011). However, Muslim Scholars have certified that life insurance is unlawful in Islam. It is linked with distrust of Allah and does not take into consideration that " $H e$ has

* Corresponding author.

E-mail address: jumadil.saputra@umt.edu.my (J. Saputra)

(C) 2021 by the authors; licensee Growing Science, Canada. doi: $10.5267 /$ j.dsl.2021.3.004 
decreed the moment of death of all human beings known as Qada and Qadar". Nonetheless, some Muslim scholars have argued that what is being insured is not death, but the unfortunate consequences that arise, such as widows, orphans and other members of the community who are helpless in the future (Billah, 2003). In fact, the practice of life insurance is to ensure a sense of solidarity among participants to protect the offspring of the deceased, which is encouraged by the Prophet Muhammad.

The practice of life insurance creates several issues relating to validity, with Islamic scholars noting the various pros and cons about the validity of life insurance as a financial instrument to protect individuals from unforeseen affliction. Based on their views, the practice of life insurance under common law is implementing an agreement called Tabaduli (selling and buying agreement). Thus, Islamic scholars agreed to change an agreement used in the practice of life insurance under common law to comply with the Shariah, namely Tabarru (mutual help). Islamic insurance (Takaful) creates an alternative for the practice of insurance under the common law, namely conventional insurance. The central idea under the practice of Takaful is an Islamic model with segregation between participant and shareholder funds, as the company's role is only to manage participants' funds on their behalf. The participants of the Takaful agree to pool their contributions and share the liabilities for every policyholder. The contributions (premiums) should be paid by donation (Tabarru) to eliminate the element of gharar. For instance, if one policyholder experienced misfortune and received a claim payment, it would be paid using the whole of the pool from the policyholders' contributions. It is commonly known as a mutual financial transaction between two parties, namely profit and loss sharing, where under Islamic law the practice of life insurance must be free from the elements that are prohibited and unlawful in the eyes of Shariah. In line with this discussion, it means that Takaful utilises two main principles considered essential elements from Shariah, which aims to ensure all Islamic models should comply with these principles (Tolefat, 2006).

Based on the previous discussion, although Takaful operators have been using an Islamic model, there remain some points that are missing and others that are not clear that is the concept of loss and surplus sharing that practised in the operational of Takaful to offer their life insurance product (Family Takaful). This study takes the opportunity from this issue, thus creating a new integrated model of premium that is comprehensively Shariah compliant. This study focuses on the equitylinked policy (Unit Linked Product). It is a sophisticated life insurance product in the current era that is more beneficial and profitable when compared with old life insurance products such as whole life insurance and Dwiguna combination (saving product). The equity-linked policy is a type of life insurance product that provides short or long-term investments. It creates a significant problem for actuaries to determine the rate of premium which is adequate according to a total loss that would be faced by the Takaful operator in the future.

\section{Literature Review}

\subsection{Insurance Premium}

In insurance, the rate of premium plays an important role, where it is based on the concept of pooling or sharing of loss. Black and Skipper (1994) stated the sharing of loss, in turn, involves the accumulation of a fund from amounts paid by the insured to provide benefits for the unfortunate few who suffer loss, where to establish the amount to be charged by the insurer to the insured must start with some ideas as to the likelihood of loss for the group. It shows a possible group of individuals beginning with a certain age and traces the history of the entire group year-by-year until all have died. Further, Harrington and Niehaus (2004) revealed that a fundamental principle of insurance pricing that if insurers are to sell coverage willingly, they must: i) receive premiums sufficient to cover their expected claim and administrative expenses; and ii) generate an expected profit to compensate for the charge of obtaining the capital necessary to support the sale of coverage.

In addition, Ciurel (2000) stated that insurance premiums must be adequate, which means that for a group of contracts, the money collected from policyholders, plus the interest earned on the investment of these amounts. It should be sufficient to pay all promised amounts and cover the insurance company expenses; insurance premiums must be equitable, that risk must consider each person insured; insurance premiums should not be excessive compared to the sums insured. Rejda (2008) added that the rate of premium for a life insurance policy is based on two underlying concepts, namely mortality and return on investment. However, there are three other variables to consider: the expense factor or the amount of the company adds to the cost of the policy to cover operating costs of selling insurance, investing the premiums, and paying claims. Mortality in life insurance is based on the sharing of the risk of death by a large group of people. It is used to give the company a primary estimation of how much money is needed to pay for death claims each year. The amount at risk must be known, it aims to predict the cost for each member of the group. By using mortality, the insurer can determine the average life expectancy for each age group. The return on investment is the second factor used in calculating the premium - this is return rate earnings. Companies invest the premiums in bonds, stocks, mortgages, real estate, and assume that they will earn a particular rate of investment return on these invested funds.

Next, Saputra et al., (2017) were focused on the aspect of rate setting in life insurance premium as concept and practice applied in the conventional and Takaful Insurance taking into account individual risk. Because individual risks play a crucial role in the life insurance policy and the restriction of the insurance company to predict the total risk that would be protected precisely or accurately, the consequence of the issue is the insurance company automatically would be facing a larger 
problem such as lowering of demand for insurance that affected by premium insurance which giving the influence to achieve target premium income and cause insolvency of the insurance company. The objective of this paper is to clarify and investigate the distinction calculation on setting rate of life insurance premium between conventional and Takaful (Islamic insurance) taking into account risk. Because it plays a crucial role to determine life insurance premium, this paper treats the most important topics related to the calculation of premiums for realistic insurance and annuity contracts. It was applied to quantitative analysis to achieve the objective of this study and numerical simulation. They found that the conventional and Takaful insurance applied similar techniques to calculate risk premium (term in conventional insurance) or tabarru fund (term in Takaful insurance) both determined considering pure risk through mortality risk but in the Takaful not existed the practice of interest rate in the calculation for present value and future benefit.

Besides that, they also detected that there are differences in the goal of them. First, conventional insurance, the calculation using pure risk using life function form through mortality risk intended to account for all risk will be faced by the insurance company to give protection for insurance participants and financial risk of the insurance company. Besides that, different from Takaful insurance, the mortality risk is considered to share fair value in the payment of compensation (tabarru or charity fund) by a participant to the insurance company. Takaful insurance used the contract of Al-Mudaraba, it aims to eliminate forbidden elements which exist in the practice of conventional insurance. Thus, this study also confirms that premium insurance charged by conventional life insurance is higher than by Takaful life insurance according to a numerical example. Further, for annual and accumulation of investment return demonstrated that conventional insurance is higher than Takaful insurance.

\subsection{Takaful Business Model}

The model of Takaful is generally applied to uphold a sense of solidarity among Muslims; it aims to substitute the concept of conventional life insurance that used in the practice of insurance in the current era (Fisher, 2013). Numerous products are available in the insurance market such as education, health, and general insurances. In a Takaful product, the relationship between the participant and the Takaful operator is based on some important concepts, for instance, mudarabah, wakalah, hybrid, and ta'awuni models. It is designed to eliminate the elements, which is not allowed by Shariah namely riba, gharar, and maysir (Yassin \& Ramly, 2011; Saputra et al. 2017).

This study also elaborates in detail the current Takaful Business Model. First, Mudarabah, which is also known as "profitsharing" or a surplus sharing model, makes use of any surplus after deducting all expenses and claims, sharing them between the insurance participant and insurance operator by a pre-agreed ratio. In the mudaraba model, the participant is known as a provider by virtue of his/her contribution into Takaful fund through a profit-sharing agreement with the operator, where the latter undertakes the responsibility as an entrepreneur or mudharib in running and managing the business. Besides that, after the first concept of being used by Takaful operator, there is still a problem based on the relationship between Takaful operator and participants, specifically in risk-sharing and investment activities. Following the issue, Islamic scholars have proposed a new model known as wakalah. A wakalah model is a contract of agency between the insurance operator and participant of insurance where the earlier appoints the latter to manage the contributions paid. This model involves the participant appointing the insurance operator as his agent to run and manage his or her funds for both risk-sharing and investment activities.

In this model, the insurance operator charges an up-front fee, known as wakalah, for services to be rendered. The net of funds or surplus from underwriting after deducting claims and direct expenses will be used for investments and the profit obtained from investment funds will be distributed according to a pre-agreed ratio, if one exists. In the wakalah model, the surplus of policyholders' funds and investments, minus the management fee or expenses, goes to the policyholders. The shareholders charge a wakalah fee from contributions and this fee covers most of the expenses of the business. The fee rate is fixed annually, in advance, and in consultation with the company's Shariah committee. In order to give incentive for good governance, management fees are related to the level of performance (Manjoo, 2007). This model can be stated as a minor variation because this model is applicable for general and family Takaful schemes only.

Further, as the needs of insurance participants to obtain the high return from the investment activities. Thus, we are required to create a new business model applied by Takaful operator that would be offering an additional benefit and included profit then the hybrid model present such as a new business model for Takaful operator in practice today. The hybrid model is the combination of two categories of mudarabah, namely pure mudaraba, and modified mudarabah. Where the pure mudaraba model allows profit-sharing on investment profit only, the modified mudaraba model between insurance participants and Takaful operator obtains sharing profit from investment profit and underwriting surplus. Based on this model, insurance operators may be seen to "gain more" under a modified mudarabah model when compared to a pure mudaraba model. Furthermore, following some approaches that have been implemented in the relationship between Takaful operators and insurance participants, a new model in Takaful business has appeared, originating from Sudan and Saudi Arabia and known as Ta'awuni, or cooperative insurance. 
Cooperative insurance, or Ta' $a w u n i$, emphasizes cooperation where donors contribute to the fund, which is used to generate profit through net surplus situations after deduction of claims payment. In this model, profits that are obtained from investment activities are shared accordingly between the operator and contributors. The profit distributed in this model does not include deduction of expenses such as staff cost, establishment, and administrative charges. It means that the profit distributed to customers is actually from gross profit. The expenses will instead be deducted from the operator's share of the profit, which means that the return to the operators is a net profit after deduction of expenses.

\section{Materials and Methods}

In this section, we will elaborate on and discuss the design of this study applied to achieve the objectives proposed. A quantitative approach is used to empirically test and simulate a new model of the premium for Family Takaful. The premium would be calculated by using new modelling of the premium for the Family Takaful (Saputra et al., 2017). The basic model of insurance that has advanced in practice is the Brownian motion model. The model was developed to solve a problem faced by insurance companies and corporations concerning risks in financial markets. The model created by Merton (1971) and Samuelson (1969), as extensions to the single horizon market models of Markowitz (1959) and Sharpe (1964), was concerned with the concepts of financial assets and markets and used continuous-time models with stochastic processes. Insurance companies need credible approaches to measure and manage risk exposure in-line with market price fluctuations including the foreign exchange rate, commodity prices, and stock prices. This model of insurance takes into account the issue of the financial market. Insurance firms began to invest their assets in two forms: some in risk-free assets and others in riskier assets. The basic assumptions include no transaction costs, no taxes, and the ability of assets to be traded continuously over time. In the stochastic differential equation for the prices of risky investment through geometric Brownian motion, the formula can be written as follows:

$$
d S(t)=\mu S(t) d t+\sigma S(t) d W(t) \mathrm{S}(0)=\mathrm{S}_{0}
$$

where, $\mu$ denotes the drift, the volatility of the process is notated by $\sigma$, and $W$ is a continuous time stochastic process (Wiener Process). From Eq. (1), the price of the risk-free asset can be determined, written as follows:

$$
d B(t)=r B(t) d t
$$

where the continuous risk-free rate compounded is denoted by $r$, where $r$ is less than $\mu$. Under this model, the assets have prices that evolve continuously over time and are driven by the Brownian motion process. In this paper, we derive and substitute some elements that are not applicable or not allowed in the Islamic financial system. Thus, we redefine the application of interest rate denoted by " $r$ " in the formula as the appropriate probability cost of sellers in the financial market (Vogel \& Hayes, 1998). Then, the model of premium considers Sharī ah compliance in the practice of takäful life insurance, correcting the default approach to apply the system of tabarru' and payoff dividend for the insured if they are still alive at the maturity of the contract. We also utilize a standard actuarial notation (Bowers, Gerber, Hickman, Jones, \& Nesbitt, 1997), $T(x)$ which denotes the random future lifetime of the insured, aged $x$, with the probability density function existing and assuming that $T(x)$ is independent of all random financial variables. Considering the mortality risk regarding the survival probability at the level of age, i.e. ${ }_{t} p_{x}$ is the likelihood that the insured is still alive at time $t$. Then, for the probability that the insured is not alive at time $t$ is denoted as ${ }_{n} q_{x}$ or can be calculated by, $1-{ }_{t} p_{x}$. In this setting, it assumed that the policyholder has agreed to pay continuous payments, denoted by $P$, and that the payment received at the beginning of the year, for $n$ years. It shows the regular premium that should be paid by the policyholder. This equally spaced length of interval time $\Delta t$ (or range of interval time) is the value at $T$ divided by $n$. Thus, the date of premium payment periodically is $t_{i}=i . \Delta t$ where $i=0, \ldots, n-1$. Furthermore, the premium regularly paid by the participant would be invested in the reference fund. Thus, following this assumption, the payoff obtained by the policyholder at the maturity of the contract is following the maximum reference fund and guarantee amount, the formula for which is given below:

$$
G R(T)=C D \frac{e^{g(T-\Delta t)}-e^{g(\Delta t)}}{e^{g(\Delta t)}-1}
$$

In simple form, the above equation can rewritten as follows:

$$
G R(T)=\sum_{i=0}^{n-1} C D e^{g\left(T-t_{i}\right)}
$$

where $G R(T)$ is the payoff obtained by the policyholder at the maturity of the insurance contract with time horizon $T$; $C D$ denotes the contribution given in the reference fund, and $g$ is the value guarantee force for the appropriate probability cost by the seller. If $g=0$, then the minimum value guarantee would be paid to the policyholder at the maturity of an insurance contract, following the time of the contract multiplied by the contribution given. Equation (4) indicates that periodical payment of premium starting at $i=0,1,2, \ldots, n-1$, would affect the amount of contributions given to increase every year, and the maximum value received is based on the time of the insurance contract. These are assumed by ignoring the application of present value for future benefit and loss. Further, the value of the reference fund is denoted by $R F(T)$. To 
calculate benefits payable to the policyholder if alive at time $t$, we use $t=m+1, \ldots, n$ which is a quantity dependent on the value invested in the portfolio. The benefits payable can be set equal to $C(T)=\max (R F(T), G R(T)$. This shows that the terminal value of the policy payoff is decomposed as the value of the minimum guaranteed rate plus the benefits payable at the maturity of the contract. This uses a European call option written on the reference fund with an exercise price equal to a minimum of the value of the guaranteed rate. The formulation can be written as $C(T)=\max (R F(T)-G R(T), 0)$.

Further, for another possible decomposition for benefits payable at the maturity of the insurance contract is the European put option, which can be set equal to $P(T)=\max (G R(T)-F R(T), 0)$. In this setting, to create a fair value of periodical premium for takâful life insurance at the inception of the equity-linked policy, the decomposition of the European call and put option is considered. Based on financial economics, the evaluation framework is assumed following a completely frictionless market; there is no arbitrage opportunity because the expected value of the change in the asset for a whole period is equal to zero. It shows the existence of a unique equivalent martingale measure, denoted by $E^{Q}$, and each contingent claim is evaluated using discounting at the appropriate probability return of the seller in the financial market. In the current paper, we assume that there is no application of a risk-free rate because it is not allowed and does not comply with the Sharī'ah. Therefore, we substitute the implementation of a risk-free rate, denoted by $r f$ in our equation, and replace it with an appropriate probability return of the seller in the financial market by using a new notation, $R p$ and the expected operator under the equivalent martingale measure $E^{Q}$ of contingent claims at the maturity of the contract.

We adopt and extend the Geometric Brownian Motion formula and assume the evolution of the reference fund value and period of premium payment with upward jumps of magnitude in the given contribution. The new equation can be set equal to:

$$
d R F(t)=R p R F(t) d t+\sigma R F(t) d W(t)
$$

Thus, following the assumption in this setting, the periodical premium paid by policyholders can be written as follows:

$$
R F\left(t_{i}\right)=R F\left(t_{i}\right) d t+C D \quad \mathrm{t}_{\mathrm{i}}<\mathrm{t}<\mathrm{t}_{\mathrm{i}+1}, i=0, \ldots, n-1
$$

where $\operatorname{RpRF}(t)$ is the appropriate opportunity return of the seller in a reference fund at time $t$, the volatility of the reference fund at time $t$ is denoted by $\sigma R F(t)$, and where $W(t)$ is a standard Geometric Brownian motion under a risk-neutral probability measure (Wiener process) and the contribution given is denoted by $C D$. Then, the fair value of the insurance scheme using the expectation operator under an equivalent martingale measure can be obtained as the present value of the guaranteed amount and the value of the call option, formulated as follows:

$$
E_{t}^{Q}(G R(T)+C(T))=E_{t}^{Q}(G R(T))+E_{t}^{Q}(C(T))
$$

where, $E_{t}^{Q}($.$) represents the expectation operator value at the start of the insurance scheme against contingent claims under$ a risk-neutral probability measure. $E_{t}^{Q}(G R(T))$ is computed using the discounting at the appropriate opportunity return of the seller from the investment fund in a fixed guarantee $G R(T)$, as below:

$$
E_{t}^{Q}\left(G R(T)=e^{-R p(T)} C D\left(\frac{e^{g(T-\Delta t)}-e^{g(\Delta t)}}{e^{g(\Delta t)}-1}\right)^{2}\right.
$$

The computation of the call option value at the inception of insurance coverage is more complicated and difficult due to the upward jumps in the reference fund value dynamics. Hence, the issue of insurance coverage must be dealt with as an important part of the insurance product. In this setting, we also introduce a new mortality derivative and create a new formula for calculating the rate of mortality to determine a tabarru' premium, which is derived from the basic mortality formula advanced in the practice of insurance companies (Bowers et al., 1997; Rejda, 2008), changing some parts which are not allowed in view of Islamic law. For this, we use the basic formula to determine mortality risk, i.e. life function through a mortality table. It is calculated using the probability of life and death. The probability value of people being alive or dead at $t$ can be written as below:

$$
{ }_{n} p_{x}=\frac{l_{x+1}}{l_{x}} \quad \text { and } \quad{ }_{n} q_{x}=\frac{l_{x}-l_{x+1}}{l_{x}}=1-{ }_{n} p_{x}
$$

From Eq. (9) and Eq. (10), we found some missing points in the practice of insurance generally. We replace the statement "fair value", which comes from the sum of insurance coverage offered and multiplying it with the annual premium. In this setting, we change a term familiar to insurance companies using moving windows. Eq. (9) can be simplified and set up equal to: 
${ }_{n} q_{x}=\frac{l_{x=0}-l_{x+1}}{l_{x=0}}=1-{ }_{n} p_{x}$

Then, from Eq. (10), we find a margin from the probability value of death at time $t$. Following the above issue, this Sharī'ahprohibited type of speculation is adopted by takâful life insurance to determine the risk premium. Thus, we eliminate the issue relating to the probability of life using moving windows. From equation (10), we create a new equation to calculate mortality risk. It can be seen as follows:

$$
{ }_{n} \bar{q}_{x}=\frac{l_{x+t}-l_{x+1}}{l_{x+t}}=1-{ }_{n} p_{x} \quad \text { where, } t=0,1,2, \ldots, n .
$$

Further, the total probability of an individual's death can be set equal to:

$$
{ }_{n} \bar{q}_{x}=\sum_{i=0}^{n}\left(\frac{l_{x+t}-l_{x+1}}{l_{x+t}}\right)
$$

Proposition (1): Eqs. (10 and 11) indicate that the moving window on a new formula has a positive effect on the probability value of death at the beginning of the year. It means that the application of the equation would reduce the risk of an insurance company in the operational and default probability of risks. Further, we can use Eq. (12) risk premium (tabarru' premium) model and develop this to take account of sharing risk among participants:

$$
{ }_{n} \widetilde{q}_{x}=\sum_{i=0}^{n}\left[C D \frac{e^{g(T-\Delta t)}-e^{g(\Delta t)}}{e^{g(\Delta t)}-1}\right] * 1\left(\frac{1}{1+r}\right)^{n} *\left({ }_{n} \bar{q}_{x}\right) * n
$$

Furthermore, to set up the tabarru ' premium that should be paid by the participant, we get:

$$
{ }_{n} \widetilde{q}_{x}=\max \left(\sum_{i=0}^{n}\left[C D \frac{e^{g(T-\Delta t)}-e^{g(\Delta t)}}{e^{g(\Delta t)}-1}\right] * 1\left(\frac{1}{1+r}\right)^{n} *\left({ }_{n} \bar{q}_{x}\right) * n\right)
$$

where the tabarru ' premium is denoted by ${ }_{n} \widetilde{q}_{x}$, the $C D$ is the contribution given, $r$ is appropriate probability cost by the seller, $n$ is a time of the contract, $g$ is the guaranteed value rate of return from the investment, ${ }_{n} \bar{q}_{x}$ is the new mortality derivative applied moving windows.

Proposition (2): equations (13 and 14) show the contribution given, mortality derivative, appropriate probability cost by the seller and time of contract which offers a positive effect to the worth of the tabarru ' premium. Nevertheless, at the same time, it would increase the sum of insurance coverage. Following Eq. (14), the tabarru' premium would be paid by the participant at the beginning of the year using the maximum value of risk. Also, the product created should consider the terminal wealth of participants through the sum of insurance coverage. Thus, if the policyholder needs the sum of the insurance to be large, then the participant should pay a higher tabarru' premium. It can be concluded that the sum of insurance coverage affects the rate of the tabarru premium, and should be paid by the participant periodically. It is can be set up as follows:

$$
{ }_{n} \widetilde{q}_{x}=\max \left(\sum_{i=0}^{n}\left[C D \frac{e^{g(T-\Delta t)}-e^{g(\Delta t)}}{e^{g(\Delta t)}-1}\right] * 1\left(\frac{1}{1+r}\right)^{n} *\left({ }_{n} \bar{q}_{x}\right) *(n * k)\right)
$$

where $k$ is the number of multiplication periods in the insurance contract. Further, to determine the fair periodical premium, we compute an analytical approximation of the European call option on the underlying asset that pays fixed (negative) dividends at each premium payment period. The simple model for evaluating an option written on stock-paying fixed discrete dividends can be solved using the escrowed model. The escrowed model is based on the idea where future profits are considered in advance, and the present value may be added to the current underlying asset price. Then, using the adjusted current price, the dynamics of underlying asset prices without the upward jumps are induced at each premium payment date for the product. The formula can be set equal to:

$$
d \overline{R F}(t)=R p \overline{R F}(t) d t+\sigma \overline{R F}(t) d W(t)
$$


where, $R p \overline{R F}(t)$ is the appropriate opportunity return of the seller in a reference fund ignoring the upward jumps at time $t$, then, the volatility in a reference fund for the rate of return and ignoring the upward jumps at the time $t$ is denoted by $\sigma \overline{R F}(t)$, and $W(t)$ is a standard Geometric Brownian motion under a risk-neutral probability measure (Wiener process). Using Eq. (16) in the simple form, we get:

$$
\overline{R F}(0)=R F(0)+\sum_{i=1}^{n-1} C D e^{-R p\left(t_{i}\right)}
$$

Further, from Eq. (18), we get another value of the reference fund, written below:

$$
\overline{R F}(0)=C D \frac{1-e^{-R p(T)}}{1-e^{-R p(\Delta t)}}
$$

Proposition (3): Eq. (17) shows the fluctuation of the reference fund with upward jumps of time equal to zero (0). It would increase the value of the reference fund at each time. If the time of the reference fund is equal to zero, then the value of the reference fund is equal to $C D$. At the same time, Eq./ (18) indicates the fluctuation of the reference fund without upward jumps at the beginning of the year equal to $C D$. Nevertheless, the total value of the reference fund (Eq. (19)) would be smaller than the reference fund with upward jumps at the end of the year. By using the adjusted current underlying asset prices, the European call option of the Black-Scholes can be written as follows:

$$
E_{t}^{Q}(C(T))=\overline{R F}(0) \Phi\left(d_{1}(t)\right)-G R(T) e^{-R p(T)} \Phi\left(d_{2}(t)\right)
$$

In Eq. (19), the cumulative distribution function exists and the problem in the replicating portfolio at time $t$. The function of cumulative distribution can be seen as below:

$$
d \pm(t)=\frac{1}{\sigma \sqrt{T}}\left[\log \left(\frac{\overline{R F}(0)}{G R(T)}\right)+\left(R p \pm \frac{\sigma^{2}}{2}\right) T\right]
$$

From Eq. (19) and Eq. (19.1), we get the cumulative distribution function of the standard normal random variable denoted as $\Phi(d \pm(t)$. Also, the understanding of the escrowed model, in general, is consistently biased in option prices (Bos, Gairat, $\&$ Shepeleva, 2003; Costabile, 2013). The reason is that the volatility of the adjusted underlying asset price process $\hat{\sigma} \overline{R F}(t)$ is different from the volatility of $\sigma R F(t)$. It is a true process and is too big for periods before the dividends are paid, due to the increased value of underlying asset prices. Following the theoretical approach to modifying the escrowed dynamic model, it can be written as follows:

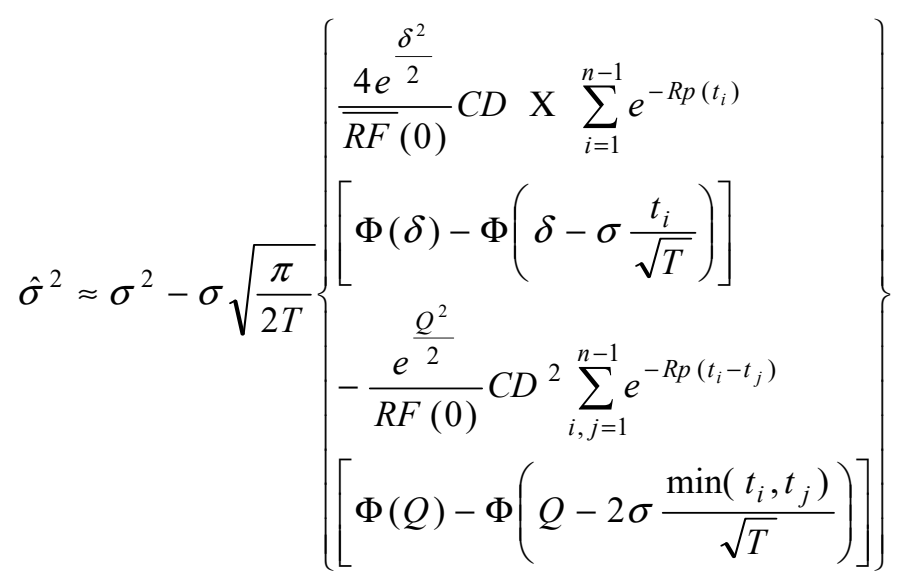

Where,

$$
\delta=\Phi(d+(t))=\frac{1}{\sigma \sqrt{T}}\left[\log \left(\frac{\overline{R F}(0)}{G R(T)}\right)+\left(R p+\frac{\sigma^{2}}{2}\right) T\right]
$$

And, 


$$
Q=\Phi(d-(t))=\frac{1}{\sigma \sqrt{T}}\left[\log \left(\frac{\overline{R F}(0)}{G R(T)}\right)+\left(R p-\frac{\sigma^{2}}{2}\right) T\right]
$$

Following equation (20), the European call option embedded in the policy value at the maturity of the insurance contract can be evaluated through the Black-Scholes model, set equal to:

$$
\hat{E}_{t}^{Q}(C(T)) \approx C_{B S}(\overline{R F}(0), G R(T), R p, \hat{\sigma}, T)
$$

Using equation (21), we insert the mudārabah concept in the premium calculation of takâful life insurance, which can be written as follows:

$$
C M=\frac{C D e^{-R p(T)}\left(\frac{e^{g(T-\Delta t)}-e^{g(\Delta t)}}{e^{g(\Delta t)}-1}\right)^{2}+\hat{E}_{t}^{Q}(C(T))}{1-e^{-R p(T)} / 1-e^{-R p(\Delta t)}}
$$

Where, $C M$ represents the contribution mudarabah, $C D$ is the contribution given that would be paid by the policyholder at the beginning of the year and annually, $R p$ is the appropriate probability of return for the seller, $g$ is the value of the guaranteed rate, and $\hat{E}_{t}^{Q}(C(T))$ is the value of the call option using Black-Scholes formula, considering the negative discrete dividend (see equation 21).

Proposition (4): equation (22) shows that the contribution mudārabah is affected by the change of $C D$ or the increasing contributions given $(C D)$. Further, the changes of the appropriate probability return of seller $(R p)$ given positive effect on the value of $C M$ and Meanwhile, the value of the guaranteed rate $(g)$ given negative effect on the value of $C M$. Further, the expenses of takäful life insurance can be formulated equally as:

$$
C_{E X}=\left(\frac{C D e^{-R p(T)}\left(\frac{e^{g(T-\Delta t)}-e^{g(\Delta t)}}{e^{g(\Delta t)}-1}\right)^{2}+\hat{E}_{t}^{Q}(C(T))}{1-e^{-R p(T)} / 1-e^{-R p(\Delta t)}}\right)-E_{t}^{Q}(C(T))
$$

where $C_{E X}$ denotes the administration cost spent by the insurance company, such as fees for agents and others, $C D$ is the contribution paid by the policyholder at the beginning of the year and annually, $R p$ is the appropriate probability return of the seller, $g$ is the value of the guaranteed rate, $\hat{E}_{t}^{Q}(C(T))$ is the value of the call option using the Black-Scholes formula considering the discrete dividend to the increased value of the underlying asset price (see equation 21$), E_{t}^{Q}(C(T))$ is the value of the call option using the Black- Scholes formula without considering the calculation of discrete dividend (see Eq. (11)).

Preposition (5): equation (23) shows the cost that should be spent by the policyholder for the life insurance product. The change of contribution given $(C D)$ would be seen as a positive effect on the value of expenses spent by the policyholder. Further, the effect of an appropriate probability return of the seller is positive; or, $R p$ increases alongside $C_{E X}$. The increase in the guaranteed rate $(g)$ value would decrease the value of $C_{E X}$.

Following the European call option embedded in the policy value at the maturity of the insurance contract through the Black-Scholes model in equation (21), the periodical premium can be set equal to:

$$
P=\frac{\left.C D e^{-R p(T)}\left(\frac{e^{g(T-\Delta t)}-e^{g(\Delta t)}}{e^{g(\Delta t)}-1}\right)^{2}+{ }_{n} \widetilde{q}_{x}\right)+C_{B S}(\overline{R F}(0), G R(T), R p, \hat{\sigma}, T)}{1-e^{-R p(T)} / 1-e^{-R p(\Delta t)}}
$$

Where $P$ represents the periodical premium, the contribution given is denoted by $C D, g$ is the guaranteed value, $R p$ is the appropriate probability return of the seller, ${ }_{n} \widetilde{q}_{x}$ is the tabarru ' premium using the derivative mortality risk developed. After that, the European call option is embedded under the equity-linked policy until the maturity of the insurance contract and this can be evaluated by the Black-Scholes model and dynamic Escrowed model (see equation 22). Then, the annual level premium payment paid by the policyholder at the beginning of the year can be written as follows: 


$$
A L P=\operatorname{Max}\left(\frac{C D e^{-r f(T)}\left(\frac{e^{g(T-\Delta t)}-e^{g(\Delta t)}}{e^{g(\Delta t)}-1}\right)^{2}+\left({ }_{n} \widetilde{d}_{x}\right)+\hat{E}_{t}^{Q}(C(T))}{1-e^{-r f(T)} / 1-e^{-r f(\Delta t)}}\right)
$$

Where $A L P$ is denoted as annual level premium, $C D$ is contribution deemed, $r_{f}$ is risk free rate, $T$ is time horizon, $\Delta t$ is equally-spaced time intervals of length, $g$ is value of guaranteed, $\left({ }_{n} \widetilde{d}_{x}\right)$ is a new mortality derivative, and $\hat{E}_{t}^{Q}(C(T))$ is the value of call option using Black-Scholes formula considered the discrete dividend to the increasing value of underlying asset price.

After calculating the rate of premium, we also added an assumption to implicate the formula in the real problem faced by Takaful operators regarding the calculation of loss sharing and profit sharing using Tabarru and Mudarabah contracts. First, we assume that the pre-agreed sharing ratio between participant and Takaful used in practice that is the profit obtained from an investment fund would be shared as much as $70: 30$ per cent or $70 \%$ for the participant and $30 \%$ for the Takaful operator (alpha is equal to $30 \%$ ). Further, to check the sensitivity of the formula regarding the change of alpha, we also use alpha $25 \%, 30 \%, 35 \%$, and $40 \%$ or $75 \%, 70 \%, 65 \%$, and $60 \%$ shared to participants. The formula can be written as:

$$
P A S R=\frac{T S U R P L S}{T G C O N T}
$$

PASR denotes Pre-Agreed sharing ratio between participant and Takaful operator, TSURPLS is the total surplus from investment, and TGCONT is the whole general contribution gathered from the participant. Following this formula, the calculation for sharing profit is explicit. Then, we can calculate the surplus sharing underwriting as follows:

$$
S U R D W=P A S R\left(\frac{T S U R D W}{T G C O D W}\right)
$$

where $S U R D W$ is the total surplus underwriting, $P A S R$ is Pre-Agreed sharing ratio between participant and Takaful operator, $T S U R D W$ is the total surplus from underwriting, and TGCODW is the total general contribution underwriting gathered from the participant.

Further, to improve missing points related to the concept of surplus underwriting by Takaful operators in the current era, this study also proposes a new concept for Takaful business model, presented below: 


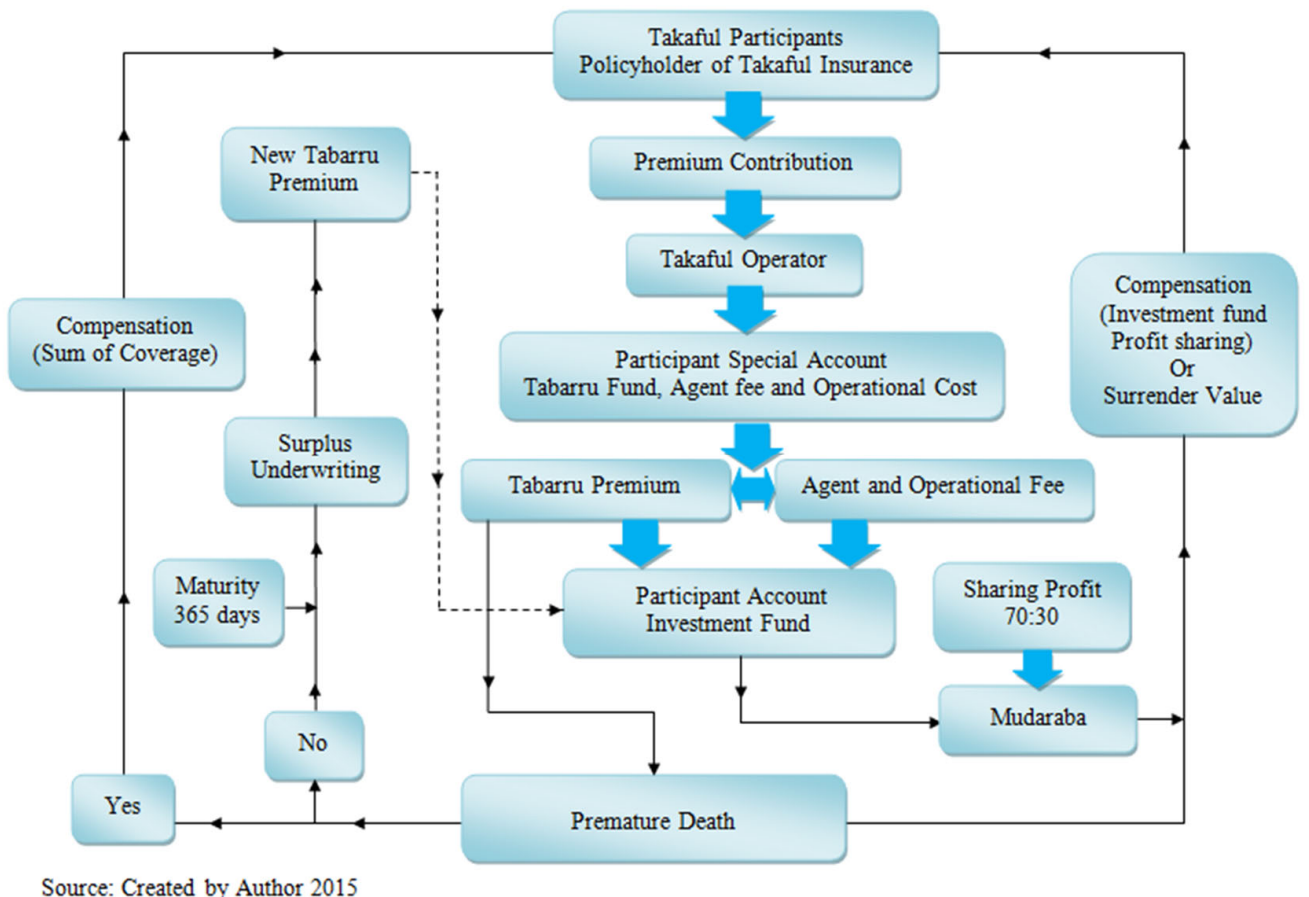

Fig. 1. A New Modeling Premium for the Takaful Business Model

The data sources in this study collected from two sources: The Bureau of Indonesia Statistic Center (BPS), and the Indonesia Stock Exchange (BEI). The data were used in an empirical analysis process running from 2009 to 2015. The algorithm process was developed and performed by using Matlab R2015.

\section{Results and Discussion}

In this study, we develop a new model of the premium for the Family Takaful, adapted and derived from the current Takaful Business Model. It was developed using a new concept of Tabarru and Mudarabah. Further, we empirically tested the model using the secondary data and applied a new mortality table of Indonesia in the year of 2011. The empirical simulation analysis followed the parameters i) the periodical insurance payment, $n=5$, ii) the time of insurance contract, $\mathrm{T}=5$, iii) the value of contribution deemed, $C D=\$ 100$, iv) the appropriate probability return of the seller, $r=0.0557$, v) the risk-free rate, $r_{f}=0.0780$, vi) the value of guaranteed rate $g=0.0350$, vii) the value of volatility for reference fund, $\sigma=0.3069$. Using the formula and algorithm process developed, an empirical simulation analysis was carried out in the form of a sales illustration product specifically for equity-linked policies (unit-linked product). The results can be seen as follows:

\section{Table 1}

The value of contribution for periodical premium at the inception of insurance under equity-linked policy

\begin{tabular}{|c|c|c|c|c|c|}
\hline \multirow{2}{*}{$\begin{array}{l}\text { Year } \\
\text { Time }\end{array}$} & \multicolumn{5}{|c|}{ Contribution Periodical Premium } \\
\hline & Premium & Discount- Premium & Excess of Premium & Pure Premium & Accumulation Premium \\
\hline 1 & 181.47 & 181.47 & 0.00 & 165.78 & 181.47 \\
\hline 2 & 181.47 & 180.64 & 0.83 & 165.78 & 362.94 \\
\hline 3 & 181.47 & 179.85 & 1.61 & 165.78 & 544.41 \\
\hline 4 & 181.47 & 179.11 & 2.35 & 165.78 & 725.88 \\
\hline 5 & 181.47 & 178.41 & 3.06 & 165.78 & 907.35 \\
\hline Total & 907.35 & 899.47 & 7.85 & 828.89 & - \\
\hline
\end{tabular}

Table 1 shows the contribution value of the periodical premium that should be paid by the policyholder at the inception of the insurance scheme under the equity-linked policy. Following the table above, we found that the periodical contribution premium paid annually would be $\$ 181.47$, giving a total premium amount for 5 years of $\$ 907.35$. Then, a discount for annual premium indicates that the contribution premium paid by the policyholder every year decreases and the total discount premium annually is $\$ 899.48$. Besides that, this study found that the excess of the amount of contribution premium received by Takaful operator is $\$ 7.85$. This issue attracts a need for attention because the excess of the annual premium is unclear in the contract. Furthermore, we also found that when a pure premium paid annually is $\$ 165.78$, the total amount of pure premium for 5 years at the maturity of an insurance contract is $\$ 828.89$, and the accumulation of periodical premium for 5 years in the inception of equity-linked policy scheme is equal to $\$ 907.35$. In this paper, we use moving windows and stoploss continuous lifetime to determine new contributions to Tabarru that should be paid by the policyholder. We need to create an additional assumption that is, (1) a pre-agreed ratio of surplus underwriting that would be shared between participants and the Takaful operator. In this case, we use alpha $25 \%, 30 \%, 35 \%$, and $40 \%$ for representing the profit of 
Takaful operator. It aims to ensure the sensitivity of pre-agreed ratio value towards the surplus underwriting (Tabarru). (2) The general contribution underwriting collected from the contribution Tabarru paid by the policyholder is $\$ 100.000 .000$, and (3) total surplus underwriting received from Islamic re-insurance that is $\$ 50.000 .000$.

Table 2

The value of participant special accounts at the inception of insurance under equity-linked policy

\begin{tabular}{|c|c|c|c|c|c|c|c|c|}
\hline \multirow[b]{2}{*}{ Alpha } & \multirow[b]{2}{*}{$\begin{array}{c}\text { Time } \\
\text { (Year) }\end{array}$} & \multicolumn{7}{|c|}{ Participant Special Account } \\
\hline & & Tabarru & $\begin{array}{c}\text { Discount } \\
\text { Tabarru }\end{array}$ & $\begin{array}{l}\text { Excess } \\
\text { Tabarru }\end{array}$ & $\begin{array}{l}\text { Discount Surplus } \\
\text { Underwriting }\end{array}$ & $\begin{array}{c}\text { New } \\
\text { Tabarru }\end{array}$ & Ujrah & Total PSA \\
\hline \multirow{6}{*}{$\alpha=25 \%$} & 1 & 15.69 & 15.69 & 0.00 & 0.00 & 15.69 & 27.54 & 43.23 \\
\hline & 2 & 15.69 & 14.86 & 0.83 & 5.88 & 9.81 & 27.54 & 37.35 \\
\hline & 3 & 15.69 & 14.08 & 1.61 & 5.57 & 10.12 & 27.54 & 37.66 \\
\hline & 4 & 15.69 & 13.33 & 2.36 & 5.28 & 10.41 & 27.54 & 37.95 \\
\hline & 5 & 15.69 & 12.63 & 3.06 & 5.00 & 10.69 & 27.54 & 38.23 \\
\hline & Total & 78.44 & 70.59 & 7.85 & 21.74 & 41.02 & 137.7 & 194.41 \\
\hline \multirow{6}{*}{$\alpha=30 \%$} & 1 & 15.69 & 15.69 & 0.00 & 0.00 & 15.69 & 27.54 & 43.23 \\
\hline & 2 & 15.69 & 14.86 & 0.83 & 5.49 & 10.20 & 27.54 & 37.74 \\
\hline & 3 & 15.69 & 14.08 & 1.61 & 5.20 & 10.49 & 27.54 & 38.03 \\
\hline & 4 & 15.69 & 13.33 & 2.36 & 4.93 & 10.76 & 27.54 & 38.30 \\
\hline & 5 & 15.69 & 12.63 & 3.06 & 4.67 & 11.02 & 27.54 & 38.56 \\
\hline & Total & 78.44 & 70.59 & 7.85 & 20.29 & 42.47 & 137.7 & 195.86 \\
\hline \multirow{6}{*}{$\alpha=35 \%$} & 1 & 15.69 & 15.69 & 0.00 & 0.00 & 15.69 & 27.54 & 43.23 \\
\hline & 2 & 15.69 & 14.86 & 0.83 & 5.10 & 10.59 & 27.54 & 38.13 \\
\hline & 3 & 15.69 & 14.08 & 1.61 & 4.83 & 10.86 & 27.54 & 38.40 \\
\hline & 4 & 15.69 & 13.33 & 2.36 & 4.58 & 11.11 & 27.54 & 38.65 \\
\hline & 5 & 15.69 & 12.63 & 3.06 & 4.33 & 11.36 & 27.54 & 38.90 \\
\hline & Total & 78.44 & 70.59 & 7.85 & 18.84 & 43.92 & 137.7 & 197.31 \\
\hline \multirow{6}{*}{$\alpha=40 \%$} & 1 & 15.69 & 15.69 & 0.00 & 0.00 & 15.69 & 27.54 & 43.23 \\
\hline & 2 & 15.69 & 14.86 & 0.83 & 4.71 & 10.98 & 27.54 & 38.52 \\
\hline & 3 & 15.69 & 14.08 & 1.61 & 4.46 & 11.23 & 27.54 & 38.77 \\
\hline & 4 & 15.69 & 13.33 & 2.36 & 4.22 & 11.47 & 27.54 & 39.01 \\
\hline & 5 & 15.69 & 12.63 & 3.06 & 4.00 & 11.69 & 27.54 & 39.23 \\
\hline & Total & 78.44 & 70.59 & 7.85 & 17.39 & 45.37 & 137.7 & 198.76 \\
\hline
\end{tabular}

Table 2 displays the value of participant special accounts at the inception of insurance under the equity-linked policy. In the above table, from the Alpha $25 \%, 30 \%, 35 \%$, and $40 \%$, we found the rate of Tabarru (donation) paid by the policyholder is $\$ 15.69$, and the total amount of Tabarru for 5 years is equal to $\$ 78.44$. Then, a discount for Tabarru indicates a lower value of contribution paid by the policyholder every year, with a total amount of discount Tabarru for 5 years of $\$ 70.59$. Besides that, this study found that the excess amount of contribution Tabarru received from Takaful operator is $\$ 7.85$. Again, the excess contribution of Tabarru is unclear in the contract. This study attempts to solve this issue by creating a new integrated model of premium, using a new mechanism to solve a problem related to the concept of Tabarru which is still unclear in the practice of Takaful operators in the current era.

Further, using these assumptions, we found that the discount surplus underwriting every year decreased for all values of alpha i.e. the total amount of a discount surplus underwriting in the inception of insurance under an equity-linked policy for alpha $25 \%$ is $\$ 21.74,30 \%$ is $\$ 20.29,35 \%$ is $\$ 18.84$ and higher than alpha $40 \%$ is $\$ 17.39$. It means that pre-agreed ratio value is sensitively (negative) towards a change of the value of discount surplus underwriting. Further, for alpha $25 \%$, the total amount of a new contribution of Tabarru at the inception of insurance under an equity-linked policy is $\$ 41.02$. Then, for alpha $30 \%$, the total amount of a new contribution of Tabarru at the inception of insurance under an equity-linked policy is $\$ 42.47$. For alpha $35 \%$, the total amount of a new contribution of Tabarru at the inception of insurance under an equitylinked policy is $\$ 43.92$. Meanwhile, for alpha $40 \%$, the total amount of a new contribution of Tabarru at the inception of insurance under an equity-linked policy is $\$ 45.37$. It means that pre-agreed ratio value $(\alpha)$ is sensitively (positive) towards a change of the value new contribution of Tabarru.

The expenditures that should be expensed by the Takaful operator in administration and operation of the company at the inception of insurance under an equity-linked policy is $\$ 27.54$, and the total amount of the expenditure for the Takaful operator in administration and operation of the company over 5 years is $\$ 137.70$ for all the value of alpha are similar. In addition, the total of participant special accounts for each alpha is experiencing an increase i.e. $25 \%$ is $\$ 194.41,30 \%$ is $\$ 195.86,35 \%$ is $\$ 197.31$, and $40 \%$ is $\$ 198.76$. It means that pre-agreed ratio value $(\alpha)$ is sensitively (positive) towards a change of the total value of participant special account.

Table 3

A comparison of the value of participant special accounts under equity-linked policy

\begin{tabular}{cccccccc}
\hline \multirow{2}{*}{ Alpha } & Time & \multicolumn{4}{c}{ Participant Special Account } \\
\cline { 3 - 7 } & (Year) & Tabarru & $\begin{array}{c}\text { Discount } \\
\text { Tabarru }\end{array}$ & $\begin{array}{c}\text { New } \\
\text { Tabarru }\end{array}$ & Ujrah & $\begin{array}{c}\text { Standard Total } \\
\text { PSA }\end{array}$ & New Total PSA \\
\hline \multirow{2}{*}{$\alpha=25 \%$} & 1 & 15.69 & 15.69 & 0.00 & 27.54 & 43.23 \\
& 2 & 15.69 & 14.86 & 9.81 & 27.54 & 43.23 & 37.35 \\
\hline
\end{tabular}




\begin{tabular}{|c|c|c|c|c|c|c|c|}
\hline & & \multirow{2}{*}{\multicolumn{2}{|c|}{14.08}} & & \multirow[b]{2}{*}{43.23} & \multirow[b]{2}{*}{37.66} \\
\hline & 3 & & & 10.12 & 27.54 & & \\
\hline & 4 & 15.69 & 13.33 & 10.41 & 27.54 & 43.23 & 37.95 \\
\hline & 5 & 15.69 & 12.63 & 10.69 & 27.54 & 43.23 & 38.23 \\
\hline & Total & 78.44 & 70.59 & 41.02 & 137.70 & 216.14 & 194.41 \\
\hline \multirow{6}{*}{$\alpha=30 \%$} & 1 & 15.69 & 15.69 & 0.00 & 27.54 & 43.23 & 43.23 \\
\hline & 2 & 15.69 & 14.86 & 10.20 & 27.54 & 43.23 & 37.74 \\
\hline & 3 & 15.69 & 14.08 & 10.49 & 27.54 & 43.23 & 38.03 \\
\hline & 4 & 15.69 & 13.33 & 10.76 & 27.54 & 43.23 & 38.30 \\
\hline & 5 & 15.69 & 12.63 & 11.02 & 27.54 & 43.23 & 38.56 \\
\hline & Total & 78.44 & 70.59 & 42.47 & 137.70 & 216.14 & 195.86 \\
\hline \multirow{6}{*}{$\alpha=35 \%$} & 1 & 15.69 & 15.69 & 0.00 & 27.54 & 43.23 & 43.23 \\
\hline & 2 & 15.69 & 14.86 & 10.59 & 27.54 & 43.23 & 38.13 \\
\hline & 3 & 15.69 & 14.08 & 10.86 & 27.54 & 43.23 & 38.40 \\
\hline & 4 & 15.69 & 13.33 & 11.11 & 27.54 & 43.23 & 38.65 \\
\hline & 5 & 15.69 & 12.63 & 11.36 & 27.54 & 43.23 & 38.90 \\
\hline & Total & 78.44 & 70.59 & 43.92 & 137.70 & 216.14 & 197.31 \\
\hline \multirow{6}{*}{$\alpha=40 \%$} & 1 & 15.69 & 15.69 & 0.00 & 27.54 & 43.23 & 43.23 \\
\hline & 2 & 15.69 & 14.86 & 10.98 & 27.54 & 43.23 & 38.52 \\
\hline & 3 & 15.69 & 14.08 & 11.23 & 27.54 & 43.23 & 38.77 \\
\hline & 4 & 15.69 & 13.33 & 11.47 & 27.54 & 43.23 & 39.01 \\
\hline & 5 & 15.69 & 12.63 & 11.69 & 27.54 & 43.23 & 39.23 \\
\hline & Total & 78.44 & 70.59 & 45.37 & 137.70 & 216.14 & 198.76 \\
\hline
\end{tabular}

Table 3 shows the results of a comparison of the value for participant special accounts under the equity-linked policy. Based on the table above $(\alpha=25 \%, \alpha=30 \%, \alpha=35 \%$, and $\alpha=40 \%)$, we found that the value of standard total participant special accounts at the inception of insurance under the equity-linked policy is $\$ 43.23$, and unchanged for the 5 years until the insurance contract is matured. Meanwhile, a new total participant special account was found to be cheaper than standard total participant special accounts at the inception of insurance under the equity-linked policy. For instance, in the second year, the value of standard total participant special accounts at the inception of insurance under the equity-linked policy is $\$ 43.23$, but the value of a new total participant special account at the inception of insurance under the equity-linked policy is $\$ 37.74$. Further, the total amount of standard total participant special accounts was $\$ 216.14$.

In addition, as aforementioned above, besides to calculate the value of participant special accounts, this study also test other values of pre-agreed ratio $(\alpha)$ such as $\alpha=25 \%, \alpha=30 \%, \alpha=35 \%$, and $\alpha=40 \%$. It aims to check the sensitivity of the change of pre-agreed ratio value. Referring Table 4.3 in $\alpha=25 \%$, we found that the value of standard total participant special accounts at the inception of insurance under the equity-linked policy is $\$ 43.23$, and unchanged for the 5 years until the insurance contract is matured. Meanwhile, for a new total participant special account, this study fluctuated every year until the end of insurance contract. Besides that, we also found that standard total participant special accounts at the inception of insurance under the equity-linked policy is $\$ 216.14$ and is greater than a new total participant special account in alpha is $\$ 194.41$. Thus, a change of pre-agreed ratio value $(\alpha)$ is sensitively (positive) towards a change of the value new total participant special accounts i.e. $\alpha=25 \%$ is $\$ 194.41, \alpha=30 \%$ is $\$ 195.86, \alpha=35 \%$ is $\$ 197.31$, and $\alpha=40 \%$ is $\$ 198.76$. In other words, a change of alpha (increase) is given a positive effect to the total value of participant special accounts. It means that when alpha increases then the value of a new total participant special account to be increased.

By using the change of value of alpha for testing a new model of premium empirically, we can conclude that a new concept and mechanism developed in a new integrated model for premium is more beneficial and profitable compared with the standard mechanism. Further, in the below table, It is shown the result of analysis for the mudarabah (profit sharing) on the participant account.

Table 4

The value of participant account at the inception of insurance under equity-linked policy

\begin{tabular}{|c|c|c|c|c|c|}
\hline \multirow[b]{2}{*}{ Alpha } & \multirow[b]{2}{*}{ Time (Year) } & \multicolumn{2}{|c|}{ Participant Account } & \multicolumn{2}{|c|}{ Surplus of Profit Sharing } \\
\hline & & Investment Fund & $\begin{array}{l}\text { Accumulation } \\
\text { Investment Fund }\end{array}$ & Mudarabah & $\begin{array}{c}\text { Accumulation } \\
\text { Mudarabah }\end{array}$ \\
\hline \multirow{6}{*}{$\alpha=25 \%$} & 1 & 138.24 & 138.24 & 51.84 & 51.84 \\
\hline & 2 & 139.90 & 278.13 & 52.46 & 104.30 \\
\hline & 3 & 141.47 & 419.60 & 53.05 & 157.35 \\
\hline & 4 & 142.95 & 562.56 & 53.61 & 210.96 \\
\hline & 5 & 144.36 & 706.91 & 54.14 & 265.10 \\
\hline & Total & 706.91 & - & 265.09 & - \\
\hline \multirow{6}{*}{$\alpha=30 \%$} & 1 & 138.24 & 138.24 & 48.38 & 48.38 \\
\hline & 2 & 139.90 & 278.13 & 48.97 & 97.35 \\
\hline & 3 & 141.47 & 419.60 & 49.51 & 146.86 \\
\hline & 4 & 142.95 & 562.56 & 50.03 & 196.90 \\
\hline & 5 & 144.36 & 706.91 & 50.53 & 247.42 \\
\hline & Total & 706.91 & - & 247.42 & - \\
\hline \multirow{2}{*}{$\alpha=35 \%$} & 1 & 138.24 & 138.24 & 44.93 & 44.93 \\
\hline & 2 & 139.90 & 278.13 & 45.47 & 90.40 \\
\hline
\end{tabular}




\begin{tabular}{|c|c|c|c|c|c|}
\hline & 3 & 141.47 & 419.60 & 45.98 & 136.37 \\
\hline & 4 & 142.95 & 562.56 & 46.46 & 182.83 \\
\hline & 5 & 144.36 & 706.91 & 46.92 & 229.75 \\
\hline & Total & 706.91 & - & 229.75 & - \\
\hline \multirow{6}{*}{$\alpha=40 \%$} & 1 & 138.24 & 138.24 & 41.47 & 41.47 \\
\hline & 2 & 139.90 & 278.13 & 41.97 & 83.44 \\
\hline & 3 & 141.47 & 419.60 & 42.44 & 125.88 \\
\hline & 4 & 142.95 & 562.56 & 42.89 & 168.77 \\
\hline & 5 & 144.36 & 706.91 & 43.31 & 212.08 \\
\hline & Total & 706.91 & - & 212.08 & - \\
\hline
\end{tabular}

Table 4 shows the empirical simulation result for participant accounts at the inception of insurance under the equity-linked policy. Similar to previous sections, we use two panels to detect the sensitivity of pre-agreed ratio (e.g. $\alpha=25 \%, \alpha=30 \%$, $\alpha=35 \%$, and $\alpha=40 \%$ ). The results of analysis found that the value of investment funds at the inception of insurance under an equity-linked policy every year fluctuates (increases). The total amount of investment fund at the inception of insurance under an equity-linked policy is $\$ 706.91$. Besides that, we also found the total value of surplus sharing (mudarabah) in alpha $25 \%$ is equal to $\$ 265.10$. It is greater than the total value of surplus sharing (mudarabah) in alpha $30 \%$ that is $30 \%$ is $\$ 247.42$. Further, the total value of surplus profit sharing for alpha $45 \%$ is $\$ 229.75$ and it is larger than the change value of alpha $40 \%$, which equals $\$ 212.08$. It means that the higher value of pre-agreed ratio would give the negative effect to the change of surplus sharing value (mudarabah). In other words, increasing the value of alpha would decrease the value of surplus sharing (mudarabah).

As aforementioned above, a new integrated model developed in this study is to solve the problem related to the concept of mudarabah (profit sharing) which is unclear in the practice of Takaful operators. We use moving windows and stop-loss continuous life time to determine a new mudarabah (profit sharing) that would be received by the policyholder from the return of investment activities which are managed by Takaful operator. Before proceeding to the setting of a new profit sharing mechanism, we need an additional assumption that is, (1) pre-agreed ratio of surplus underwriting that would be shared between participant and Takaful operator. In this case, we use alpha $25 \%, 30 \%, 35 \%$ and $40 \%$ for representing the profit of Takaful operator. It aims to ensure the sensitivity of pre-agreed ratio value towards the surplus of profit sharing (mudarabah), (2) the general contribution of investment funds is $\$ 200.000 .000$, and (3) total surplus of investment received from Islamic reinsurance is $\$ 100.000 .000$

Using these assumptions, we found that the mudarabah that would be received by the policyholder from the investment activity for every year fluctuates. For checking the sensitivity of total amount of mudarabah, this study uses the value of pre-agreed ratio (alpha) 25\%,30\%,35\%, and 40\%. Further, we compare the value of participant accounts and surplus sharing profit that is, (i) standard investment fund and (ii) new investment fund. Then, (i) standard mudarabah and (ii) new mudarabah aims to prove that a new mechanism of investment fund and mudarabah (profit sharing) proposed in a new integrated model is more profitable besides complying with Shariah. The result as shown in the table below:

Table 5

A comparison the value of participant accounts and profit sharing under an equity-linked policy

\begin{tabular}{|c|c|c|c|c|c|}
\hline \multirow[b]{2}{*}{ Alpha } & \multirow[b]{2}{*}{ Time (Year) } & \multicolumn{2}{|c|}{ Participant Account } & \multicolumn{2}{|c|}{ Profit Sharing } \\
\hline & & Standard Investment Fund & Investment Fund & $\begin{array}{c}\text { Standard } \\
\text { Mudarabah }\end{array}$ & New Mudarabah \\
\hline \multirow{6}{*}{$\alpha=25 \%$} & 1 & 138.24 & 138.24 & 48.38 & 51.84 \\
\hline & 2 & 138.24 & 145.38 & 48.38 & 52.46 \\
\hline & 3 & 138.24 & 143.44 & 48.38 & 53.05 \\
\hline & 4 & 138.24 & 143.17 & 48.38 & 53.61 \\
\hline & 5 & 138.24 & 142.90 & 48.38 & 54.14 \\
\hline & Total & 691.19 & 713.13 & 241.92 & 265.10 \\
\hline \multirow{6}{*}{$\alpha=30 \%$} & 1 & 138.24 & 138.24 & 48.38 & 48.38 \\
\hline & 2 & 138.24 & 145.38 & 48.38 & 48.97 \\
\hline & 3 & 138.24 & 143.44 & 48.38 & 49.51 \\
\hline & 4 & 138.24 & 143.17 & 48.38 & 50.03 \\
\hline & 5 & 138.24 & 142.90 & 48.38 & 50.53 \\
\hline & Total & 691.19 & 713.13 & 241.92 & 247.42 \\
\hline \multirow{6}{*}{$\alpha=35 \%$} & 1 & 138.24 & 138.24 & 48.38 & 44.93 \\
\hline & 2 & 138.24 & 145.38 & 48.38 & 45.47 \\
\hline & 3 & 138.24 & 143.44 & 48.38 & 45.98 \\
\hline & 4 & 138.24 & 143.17 & 48.38 & 46.46 \\
\hline & 5 & 138.24 & 142.90 & 48.38 & 46.92 \\
\hline & Total & 691.19 & 713.13 & 241.92 & 229.75 \\
\hline \multirow{5}{*}{$\alpha=40 \%$} & 1 & 138.24 & 138.24 & 48.38 & 41.47 \\
\hline & 2 & 138.24 & 145.38 & 48.38 & 41.97 \\
\hline & 3 & 138.24 & 143.44 & 48.38 & 42.44 \\
\hline & 4 & 138.24 & 143.17 & 48.38 & 42.89 \\
\hline & 5 & 138.24 & 142.90 & 48.38 & 43.31 \\
\hline
\end{tabular}


Table 5 shows the result of a comparison the value of participant accounts and surplus of profit sharing under an equitylinked policy. Based on the above table, we discuss a participant account related to an investment fund and surplus of profit sharing (mudarabah). We obtain two interesting findings: first, we found that the value of participant account that is a standard investment fund under the equity-linked policy is $\$ 138.24$ and goes unchanged for the 5 years until the insurance contract matures for all values of alpha $(\alpha=25 \%, \alpha=30 \%, \alpha=35 \%$, and $\alpha=40 \%)$. Meanwhile, for the value of the participant account named, a new investment fund is more profitable when compared to the value of a standard investment fund under the equity-linked policy.

For all values of alpha $(\alpha=25 \%, \alpha=30 \%, \alpha=35 \%$, and $\alpha=40 \%)$, we found that the total value of a new investment fund is $\$ 713.13$ and the value of a standard investment fund is $\$ 691.19$. Further, a new mudarabah for $\alpha=25 \%$ is $\$ 265.10, \alpha=$ $30 \%$ is $\$ 247.42, \alpha=35 \%$ is $\$ 229.75$ and $\alpha=40 \%$ is equal to $\$ 212.08$ and they are higher than the value of standard mudarabah is $\$ 241.92$. Further, by comparing the value of alpha $(\alpha=25 \%, \alpha=30 \%, \alpha=35 \%$, and $\alpha=40 \%)$, we found that a change of alpha is given a negative effect to the value of a new mudarabah. In other words, when alpha increases, then the value of a new mudarabah would decrease. It clears that the pre-agreed ratio is sensitive to the value of surplus sharing (mudarabah). It can be concluded that a new mechanism related to investment funds has been used to develop a new integrated model for premium in this study that is more profitable. Thus, a new integrated model for investment funds has solved the issue related to the participant account specifically for investment funds, which remained unclear.

Further, we found that the value of the participant account that is a standard mudarabah (profit sharing) under the equitylinked policy is $\$ 48.38$ and goes unchanged for the 5 years until the insurance contract matures. Meanwhile, the value of a participant account named a new mudarabah is more profitable when compared to the value of standard mudarabah under an equity-linked policy. For instance, in the second year, the value of standard mudarabah is $\$ 48.38$ but the value of a new mudarabah under the equity-linked policy is $\$ 52.46$. Thus, we can conclude that a new mechanism related to mudarabah (profit sharing) has developed a new integrated model for premium in this study is more profitable compared with the standard mechanism of mudarabah created by previous Islamic scholars. Then, a new integrated model for mudarabah has solved the issue relating to the participant account specifically for mudarabah (profit sharing) which was unclear. This study has contributed to a new model for Takaful business model that complies with Shariah comprehensively and is also more profitable. This study also determines the advantages of product features that can give mutual benefit for both parties. In this part, we discuss the value of surrender option, the sum of insurance coverage, underwriting, and maturity under the equity-linked policy.

Table 6

The value of surrender option, sum of insurance coverage and underwriting at the inception of insurance under equity-linked policy

\begin{tabular}{|c|c|c|c|c|c|c|c|}
\hline Alpha & $\begin{array}{l}\text { Time } \\
\text { (Year) }\end{array}$ & $\begin{array}{l}\text { Surrender } \\
\text { Option }\end{array}$ & $\begin{array}{c}\text { Sum of } \\
\text { Insurance }\end{array}$ & $\begin{array}{c}\text { Surplus } \\
\text { Underwriting }\end{array}$ & $\begin{array}{c}\text { Accumulation } \\
\text { Surplus } \\
\end{array}$ & $\begin{array}{l}\text { Surplus } \\
\text { Tabarru }\end{array}$ & $\begin{array}{l}\text { Value of } \\
\text { Maturity }\end{array}$ \\
\hline \multirow{6}{*}{$\alpha=25 \%$} & 1 & 190.08 & 2780.20 & 0.00 & 0.00 & 0.00 & 0.00 \\
\hline & 2 & 382.44 & 2780.20 & 5.88 & 5.88 & 0.00 & \\
\hline & 3 & 576.96 & 2780.20 & 5.57 & 11.46 & 0.00 & \\
\hline & 4 & 773.52 & 2780.20 & 5.28 & 16.74 & 0.00 & \\
\hline & 5 & 972.01 & 2780.20 & 5.00 & 21.74 & 4.74 & \\
\hline & Total & 972.01 & & 21.74 & & 4.74 & 998.48 \\
\hline \multirow{6}{*}{$\alpha=30 \%$} & 1 & 186.62 & 2780.20 & 0.00 & 0.00 & 0.00 & 0.00 \\
\hline & 2 & 375.48 & 2780.20 & 5.49 & 5.49 & 0.00 & \\
\hline & 3 & 566.47 & 2780.20 & 5.20 & 10.69 & 0.00 & \\
\hline & 4 & 759.45 & 2780.20 & 4.93 & 15.62 & 0.00 & \\
\hline & 5 & 954.33 & 2780.20 & 4.67 & 20.29 & 4.42 & \\
\hline & Total & 954.33 & - & 20.29 & - & 4.42 & 979.04 \\
\hline \multirow{6}{*}{$\alpha=35 \%$} & 1 & 183.17 & 2780.20 & 0.00 & 0.00 & 0.00 & 0.00 \\
\hline & 2 & 368.53 & 2780.20 & 5.10 & 5.10 & 0.00 & \\
\hline & 3 & 555.98 & 2780.20 & 4.83 & 9.93 & 0.00 & \\
\hline & 4 & 745.39 & 2780.20 & 4.58 & 14.50 & 0.00 & \\
\hline & 5 & 936.66 & 2780.20 & 4.33 & 18.84 & 4.10 & \\
\hline & Total & 936.66 & & 18.84 & - & 4.10 & 959.60 \\
\hline \multirow{6}{*}{$\alpha=40 \%$} & 1 & 179.71 & 2780.20 & 0.00 & 0.00 & 0.00 & 0.00 \\
\hline & 2 & 361.58 & 2780.20 & 4.71 & 4.71 & 0.00 & \\
\hline & 3 & 545.49 & 2780.20 & 4.46 & 9.17 & 0.00 & \\
\hline & 4 & 731.32 & 2780.20 & 4.22 & 13.39 & 0.00 & \\
\hline & 5 & 918.99 & 2780.20 & 4.00 & 17.39 & 3.79 & \\
\hline & Total & 918.99 & - & 17.39 & - & 3.79 & 922.78 \\
\hline
\end{tabular}

Table 6 demonstrates the empirical simulation result for the value of surrender option, the sum of insurance coverage, underwriting, and maturity under the equity-linked policy. The value of the surrender option depends on the investment fund and mudarabah (profit sharing). Using the approach previously tested and proved we found that the value of the 
surrender option received by the policyholder under an equity-linked policy for every year increases. Similar to the previous section, in this case, we use two values of alpha (e.g. $\alpha=25 \%, \alpha=30 \%, \alpha=35 \%$, and $\alpha=40 \%$ ). The result of analysis found that the value of the surrender option received by the policyholder for 5 years under an equity-linked policy in alpha $25 \%$ is equal to $\$ 972.01$ and for alpha $30 \%$ is $\$ 954.33$. Further, for alpha $35 \%$, the value of the surrender option received by the policyholder is equal to $\$ 936.66$. Meanwhile, for alpha $40 \%$, the value of the surrender option received by the policyholder to be lower than alpha $25 \%, 30 \%$, and $35 \%$ that is $\$ 918.99$.

Further, besides the profit that can be obtained by the policyholder from investment fund and mudarabah (profit sharing), we also consider the death benefit payable when the policyholder dies before the maturity of the contract. This product was created using several assumptions to improve and correct the model developed by previous researchers relating to a determination of guaranteed death benefit in the life insurance product. Based on the previous discussion, we found the death benefit in this model gives more beneficial results in several aspects, such as guaranteed payoff, minimum guaranteed rate. It aims to create a new product that can give mutual benefit for both parties, i.e. the Takaful operator and the participant.

We use a new approach and mechanism for calculating the guaranteed death benefit (sum of insurance coverage) that would be paid to the policyholder when a death occurs before maturity of the insurance contract. Using alpha $(\alpha=25 \%, \alpha=30 \%$, $\alpha=35 \%$, and $\alpha=40 \%$ ), we found the sum of insurance coverage under an equity-linked policy is $2,780.20$, due to the value of guaranteed rate, $g$ is assumed non-zero ( $g=0.035$ or 3.5 percent). However, if the value of the guaranteed rate is assumed to be equal to zero $(g=0.000)$, then the sum of insurance coverage/guaranteed death benefit payable in this product is $\$ 2,500.00$. Further, the surplus underwriting is an important part of the validity of life insurance because, in the practice of Takaful insurance, a conventional approach is still used by Family Takaful practitioners in the determination of premium and sales illustration products. One of the elements that remains unclear today, and which is under discussion by Islamic scholars and researchers in Takaful life insurance, is related to a sharing surplus of underwriting. In this setting, we have created a new approach and mechanism by using an integrated model for the premium.

We utilize the results to develop a new approach and mechanism that can be solving the issue of surplus sharing of underwriting. Interestingly, by using a new approach and mechanism created in this study i.e. we assume the surplus sharing underwriting for every year, normally the 1-year policy would mature and re-insurance would be refunded to the Takaful operator a surplus from total general contribution underwriting. Then, the value of surplus sharing underwriting would be deducted from the Tabarru premium that should be paid by the policyholder annually. Because in our assumption the policy insurance would mature at year 1 , the value of surplus sharing underwriting can be paid in the form of a discounting the Tabarru, thereby naming a new Tabarru premium. Further, the total amount of surplus sharing underwriting under an equity-linked policy for alpha $25 \%$ is equal to $\$ 21.74$ and for alpha $30 \%$ is $\$ 20.29$. Further, for alpha $35 \%$, the value of the total amount of surplus sharing underwriting is equal to $\$ 18.84$. Meanwhile, for alpha $40 \%$, the value of the total amount of surplus sharing underwriting to be lower than alpha $25 \%, 30 \%$, and $35 \%$ that is $\$ 17.39$. For surplus Tabarru premium, we found that the value of surplus Tabarru experiences decrease for each change of alpha ( $\alpha=25 \%$ is $\$ 4.74, \alpha=30 \%$ is $\$ 4.42, \alpha=35 \%$ is $\$ 4.10$, and $\alpha=40 \%$ is $\$ 3.79)$ after deducting surplus sharing underwriting for every year and to be cheaper than the value of surplus Tabarru premium for alpha $25 \%, 30 \%$, and $35 \%$, which would be added into the value of maturity (the value of surrender option plus the value of maturity e.g. $\alpha=25 \%$ is $\$ 998.48, \alpha=30 \%$ is $\$ 979.04, \alpha=35 \%$ is $\$ 959.60$, and $\alpha=40 \%$ is $\$ 922.78$ ). From the total value of maturity of an insurance contract, we can conclude that if the value of alpha increases, then the value of maturity of the insurance contract will be decreased. In other words, change of alpha has a negative effect on the change of value and maturity of an insurance contract.

\section{Conclusion}

We have successfully developed a new model of the premium for creating the sale of illustration products especially for the equity-linked policy by considering the properties contract of Takaful comprehensively namely, Tabarru (donation) and mudarabah (profit sharing). The aim of the study was to ensure that a new integrated model of premium developed was comprehensively Shariah compliant. This paper used a new mortality derivative which was created to solve and eliminate several elements which did not comply with Shariah and which still exist in the practice of Family Takaful for calculating and determining the mortality risk in life insurance premium. This study found that a new integrated model for premium has solved the issue related to the Tabarru (donation) which before was unclear. This study also has contributed a new model for Takaful business model that complies with Shariah. Further, a new integrated model of premium developed was more profitable and beneficial if compared with a standard model or current Takaful Business model.

\section{References}

Bacinello, A.R., Biffis, E., Millossovich, P. (2009). Pricing Life Insurance Contracts with Early Exercise Features. Journal of Computational and Applied Mathematics, 233, 27-35.

Billah, M. M. (2003). Islamic and Modern Insurance (Principles and Practices). Ilmiah Publishers, Kuala Lumpur, Malaysia. pp. 51-57.

Black, K., \& Skipper. Jr. H.D. (1994). Life Insurance, $12^{\text {th }}$ ed. Englewoods Cliffs, NJ: Prentice Hall, Inc. 
Bowers, N. L., Gerber, H. U., Hickman, J. C., Jones, D. A., \& Nesbitt, C. J. (1997). Actuarial Mathematics. $2^{\text {nd }}$ ed., Schaumburg, Illinois, US: The Society of Actuaries.

Ciurel, V. (2000). Insurances and Reinsurances: theoretical and practical international Approaches. All Beck Publishing House, Bucharest.

Fisher, O. C. (2013). A Takaful Primer: Basics of Islamic Insurance. Dubai, UAE: Thomson Reuters.

Hardy, M. (2003). Investment guarantees: modeling and risk management for equity-linked life insurance (Vol. 215). John Wiley \& Sons.

Harrington, S.E., \& Niehaus G.R. (2004). Risk Management and Insurance. $2^{\text {nd }}$ ed. New York: McGraw-Hill/Irwin.

Khorshid, A. (2004). Islamic insurance: a modern approach to Islamic banking. Routledge.

Manjoo, F. (2007). Risk Managemen: A Takaful perspective. Published by Alnoor, Kensington, South Africa.

Markowitz, H. M. (1959), Portfolio Selection: Efficient Diversification of Investments, New York: John Wiley \& Sons.

Merton, R. C. (1971), Optimum Consumption and Portfolio Rules in a Continuous-Time Model, Journal of Economic Theory, 3, pp. 373-413.

Matsawali, M. S., Abdullah, M. F., Yeo, C. P., Abidin, S. Y., Zaini, M. M., Ali, H. M., ... \& Yaacob, H. (2012). A study on takaful and conventional insurance preferences: The case of Brunei. International Journal of Business and Social Science, 3(22).

Qureshi, A. A. (2011). Analyzing the Sharieah Compliant Issues Currently Faced By Islamic Insurance. Interdisciplinary Journal of Contemporary Research in Business, 3(5), 279-295.

Rejda, G.E. (2008). Principles risk management and insurance. $10^{\text {th }}$ ed. Boston: Pearson Education.

Saputra, J., Kusairi, S., \& Sanusi, N. (2017). Modeling the Premium and Contract Properties of Family Takaful (Islamic Life Insurance). Journal of King Abdulaziz University: Islamic Economics, 30(2).

Samuelson, P. A. (1969), Lifetime Portfolio Selection by Dynamic Stochastic Programming, Review of Economics and Statistics, 51(3), 239-246.

Sharpe, W. F. (1964). Capital asset prices: A theory of market equilibrium under conditions of risk. The Journal of Finance, $19(3), 425-442$.

Tolefat, A. (2006). Mixed Model is Best Approach. No. 6. ICMIF Takaful.

Vaughan, E. J., \& Vaughan, T. (2007). Fundamentals of risk and insurance. John Wiley \& Sons.

Vogel, Frank. E., \& Hayes, S. L. (1998), Islamic Law and Finance: Religion, Risk, and Return, Arab and Islamic Law Series, The Hague, London, Boston: Kluwer Law International.

Yassin, N., \& Ramly, J (2011). Takaful: a study guide. 1st ed. Kuala Lumpur: IBFIM, c2011 ISSBN: 9789670149097/ 9789670149080.

Zhou, C., \& Wu, C. (2008). Optimal insurance under the insurer's risk constraint. Insurance: Mathematics and Economics, $42,225-260$.

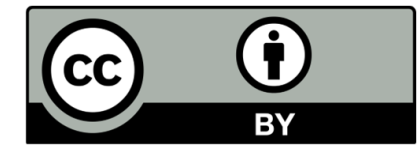

(C) 2021 by the authors; licensee Growing Science, Canada. This is an open access article distributed under the terms and conditions of the Creative Commons Attribution (CC-BY) license (http://creativecommons.org/licenses/by/4.0/). 